\title{
IDENTIFICATION OF INTERFUNCTIONAL COORDINATION ITEMS IMPORTANT FOR BUSINESS PERFORMANCE OF SMES
}

\author{
Zuzana Hübnerová1, Eva Tomášková ${ }^{2}$, Josef Bednářr ${ }^{1}$ \\ ${ }^{1}$ Institute of Mathematics, Faculty of Mechanical Engineering, Brno University of Technology, Technická 2896/2, \\ 61669 Brno, Czech Republic \\ 2 Department of Financial Law and Economics, Faculty of Law, Masaryk University, Veveři 158/70, 61180 Brno, \\ Czech Republic
}

Link to this article: https://doi.org/10.11118/actaun202068010169

Received: 16. 10. 2019, Accepted: 19. 12. 2019

To cite this article: HÜBNEROVÁ ZUZANA, TOMÁŠKOVÁ EVA, BEDNÁŘ JOSEF. 2020. Identification of Interfunctional Coordination Items Important for Business Performance of SMEs. Acta Universitatis Agriculturae et Silviculturae Mendelianae Brunensis, 68(1): 169-179.

\begin{abstract}
This paper provides a deeper analysis of the relationships between interfunctional coordination (IFC) and business performance (BP). IFC is studied in many fields such as marketing, management, logistics, informatics or human resources. The novelty lies in offering an original perspective on IFC and its impact on individual items of BP. The statistical analysis of the relationship between IFC and BP is based on a survey of small and medium-sized manufacturers. Sufficient models were identified by a stepwise backward procedure based on Akaike information criterion (AIC). The results show that it is possible to find a sufficient model for each item of BP. Sets of IFC items with exclusively positive or negative influence on at least two BP items were identified. These items of IFC are aimed on cooperative arrangement, expertise, leadership style, coordination activities and control. This research brings theoretical contributions and can be useful for managers.
\end{abstract}

Keywords: interfunctional coordination, business performance, SME, logistic regression, model

\section{INTRODUCTION}

It is of advantage for business managers to know, which activities and processes relate to each other or on the contrary, and which are independent of each other. In this sense, one of the often-mentioned approaches is interfunctional coordination (IFC). According to Tay and Tay (2007), IFC presents a harmonization of all internal functions and processes in a company. The main goal of IFC is an effective flow of information within the company itself and between the company and its environment. Therefore, companies targeting business performance (BP) improvement can benefit from applying IFC.

IFC is of scientific interest in many fields such as marketing, management, logistics, informatics, or human resources. It is one of the most important parts of market orientation. This paper aims at one of the current issues connected with IFC. The main goal of this article is to find out if it is possible to determine items of IFC which have the main impact on items of BP. Based on an empirical study, it offers a deeper analysis of the relationship between IFC and BP by determining particular models related to IFC and BP. The novelty of this paper lies in offering an original perspective on IFC and its impact on individual items of BP. Current literature does not cover such an analysis. We believe that there are both theoretical implications as well as practical applications of the revealed conclusions.

\section{Literature Review}

The term IFC has been in used for around fifty years. The first available information regarding IFC emerged at the beginning of the 1970s and 
was connected with intercompany cooperation in the sense of supply chain management. Lawrence and Lorch (1967) presented the first definition of IFC from a marketing point of view, where it was defined as the integration of sale quality and cooperation between different departments.

A new dimension of IFC emerged in connection with market orientation at the beginning of the 1990s. IFC is one significant part of market orientation being necessary for the implementation of market orientation. The implementation of market orientation is based on the total relation of company philosophy and integration of all activities, leading to the achievement of maximal value for customers. Min et al. (2007) presented that market orientation and supply chain management are based on IFC and improve BP. Some authors believe that customer orientation and IFC are the most important components of market orientation (for example Hajjat, 2002; Helfert et al., 2002; Vázquez et al., 2002). Current approach to market orientation is based on good relationship with all stakeholders. According to Ubrežiová et al. (2017), a company that is aimed on stakeholders will anticipate better the potential risks and respond effectively to the changes that may occur. Mohr et al. (2014) noted that IFC is a fundamental aspect of market orientation. It involves gaining information about the market, dissemination of information, integration of knowledge and the response to this information in the sense of coordination of activities. Generally, IFC in market orientation is understood as coordination in the use of resources and the creation of higher value for customers in the buying process (Narver and Slater, 1990; Montoya-Weiss et al., 2001). Maltz and Kohli (1996) stated that responsibility is necessary for information dissemination. Following that, it is possible to (1) cooperate with anybody from the company, (2) standardize processes, (3) integrate organization structure and enable integration of information flows, resources, processes or services in a company, (4) implement decisions and obtain control, and (5) attract experts for necessary participation.

Caruana and Calleya (1998) offered the next view on IFC. According to them, it is the main criterion of internal marketing. In the first decade of the $21^{\text {st }}$ century, IFC is perceived as communication. Zahra and George (2002) noted that IFC integrates formal and informal mechanisms of social adaptation. Baker and Sinkula (2009) showed that IFC helps companies with the transformation to learning organizations. It is the main channel for communication with customers. Woodside (2005) noted that IFC helps in communication with employees, their thinking and cooperation to reach the goals, effectivity, competitive advantage, and an increase of BP. The second part of the first decade produces two different views on IFC. First, IFC is perceived as the instrument for sharing information, cooperation between departments and coordination of companies' activities (for example Tay and Tay, 2007). Second, IFC involves sharing information, the cooperation of companies' activities and also the sharing of resources (for example Bouranta et al., 2005; Peng and George, 2011).

The latest scientific studies analyse IFC from the internal marketing point of view (for example Kaura et al., 2015), relationship to employees (for example Mohsen and Eng, 2013) or emphasis on the flexibility of IFC because IFC is based on flexibility (Carrasco et al., 2016; Wang et al., 2017). Wang et al. (2017) introduced a streamlined IFC, which is based on an implementation reducing coordinative intensity in information exchange and facilitating the relational flows in relationship exchange. This IFC enhances BP through improved flexibility and lower costs.

The relationship between IFC and BP is covered especially in the studies dealing with market orientation. IFC is one of the most important parts of market orientation and scientific studies measure the impact of total market orientation on BP. Generally, these pieces of research show the positive influence of market orientation on BP, for example (Narver et al.,1990; Kohli et al., 1993; Gray et al., 1998; Akimova, 2000; Vázquez et al., 2002; Woodside, 2005; Menguc and Auh, 2008; Salyova et al., 2015).

Only a few studies deal with IFC and BP from a logistics or supply chain management point of view. A significant study was written by Mentzer (2001). Mentzer (2001) showed that IFC has a positive impact on competitive advantage (including reduced cycle time and new product success) and profitability. Kozlowski and Bell (2003) mentioned that managers have to be competent in using the formal and informal emergent elements of the coordination mechanisms at their disposal to enact coordination effectively. Supporting the idea is that managers' coordination skills are a key behavioral ability of a cross-functional team that might lead to better team performance. Pavláková Dočekalová et al. (2018) stress that it is possible to divided social performance in two factors; the first one is care for employees and customers and the second is connected with ethical corporate behaviour. This good social performance will have an advantage of companies in the future. According to Dezso et al. (2012), coordination helps managers to coordinate their expertise and activities more effectively even if they have not cooperated before. Grimmer et al. (2017) noticed that business information systems and access to financial capital are positively related to performance.

Many studies confirmed that IFC, in general, has a positive influence on BP, although there are some IFC activities which may not be advantageous for the companies (Wang et al., 2017). Szymanski and Henard (2001) stress that maximal coordination 
and flexibility may result in increased costs caused by the implementation and maintaining of the whole system.

The results mentioned above imply our research question: "Is it possible to find a sufficient model involving items of IFC contributing to a higher level of business performance?” To our best knowledge, this approach has not been applied yet. The model might show which items of IFC contribute to the highest value of BP and model might identify items of IFC with a negative influence on BP. Lastly, items of IFC without any influence on BP might be found.

\section{MATERIALS AND METHODS}

\section{Research Design}

Our IFC related research is based on a questionnaire. The items of the questionnaire are selected based on results of a previous research (Tomaskova, 2005; Mentzer, 2001; Homburg and Pflesser, 2000) and extended by adding new items. The section of the questionnaire connected with IFC includes 22 items, see Tab. I. It is possible to divide IFC into narrower and wider conceptions. The narrower, core, conception corresponds to coordination. The wider conception relates to all activities and processes connected with the narrower conception of IFC. The individual IFC elements are listed in Tab. I.

Our IFC questionnaire was a part of a larger questionnaire focusing on IFC and services. It had a five level Likert scale form. The section related to BP involves five items, three of them focus on marketing performance and two items on financial performance. The Likert scale was used for measuring BP again. There are two reasons for this. First, a correlation between subjective and objective methods for measuring BP has been confirmed; for example (Geringer and Herbert, 1991; Harrison-Walker, 2001) or (Tang and Tang, 2012). The second reason is the unified visual conception.

I: Description of IFC items

\begin{tabular}{|c|c|c|c|}
\hline Conception & IFC elements & Notation & Question \\
\hline \multirow{14}{*}{ Widerr } & \multirow{2}{*}{$\begin{array}{l}\text { Cooperative } \\
\text { Arrangement }\end{array}$} & $\mathrm{X} 1$ & We monitor activities connected with different types of business separately. \\
\hline & & $\mathrm{X} 2$ & Activities of every department and every worker are clearly defined. \\
\hline & \multirow{2}{*}{ Expertise } & X3 & We pay attention that important posts are taken by experienced specialists. \\
\hline & & $\mathrm{X} 4$ & We focus on further education of our workers. \\
\hline & \multirow[t]{2}{*}{ Communication } & $\mathrm{X} 5$ & $\begin{array}{l}\text { We organize meetings and discuss any issues with the middle and lower- } \\
\text { level management regularly. }\end{array}$ \\
\hline & & $\mathrm{X} 6$ & We analyse any comments from our workers. \\
\hline & \multirow{2}{*}{ Leadership style } & $\mathrm{X} 7$ & We prefer teamwork and mutual cooperation. \\
\hline & & $\mathrm{X} 8$ & The relationship between superiors and subordinates is not strict and formal. \\
\hline & \multirow{2}{*}{$\begin{array}{l}\text { Ethics } \\
\text { and Goodwill }\end{array}$} & X9 & We reflect business ethics and take ethical decisions. \\
\hline & & $\mathrm{X} 10$ & Workers identify with the company and promote its image. \\
\hline & \multirow[t]{2}{*}{ Company Culture } & $\mathrm{X} 11$ & $\begin{array}{l}\text { The external environment is more important for us than the internal } \\
\text { environment. }\end{array}$ \\
\hline & & $\mathrm{X} 12$ & We favour innovations. \\
\hline & \multirow{2}{*}{$\begin{array}{l}\text { Organizational } \\
\text { Structure }\end{array}$} & $\mathrm{X} 13$ & Every worker knows her/his competence and responsibility. \\
\hline & & $\mathrm{X} 14$ & We aim at being flexible. \\
\hline \multirow{6}{*}{$\begin{array}{l}\text { Narrower } \\
\text { (Coordination) }\end{array}$} & \multirow{2}{*}{$\begin{array}{l}\text { Coordination } \\
\text { activities }\end{array}$} & $\mathrm{X} 15$ & We gain and analyse any important information regularly. \\
\hline & & $\mathrm{X} 16$ & We apply the gained information in our decisions. \\
\hline & \multirow{2}{*}{$\begin{array}{l}\text { Fundamental } \\
\text { Information } \\
\text { Acquisition }\end{array}$} & $\mathrm{X} 17$ & $\begin{array}{l}\text { We take up a positive attitude towards all information advised by our } \\
\text { stakeholders. }\end{array}$ \\
\hline & & $\mathrm{X} 18$ & We check any information on new potential resources. \\
\hline & \multirow{2}{*}{$\begin{array}{l}\text { Information } \\
\text { Coordination }\end{array}$} & X19 & $\begin{array}{l}\text { We focus on the information coordination between all company's } \\
\text { departments. }\end{array}$ \\
\hline & & $\mathrm{X} 20$ & $\begin{array}{l}\text { We focus on information coordination between the company and its } \\
\text { environment. }\end{array}$ \\
\hline \multirow[t]{2}{*}{ Widerr } & \multirow[t]{2}{*}{ Control } & $\mathrm{X} 21$ & $\begin{array}{l}\text { We prefer long-term to short-term goals, and gaining a market share to } \\
\text { financial goals. }\end{array}$ \\
\hline & & $\mathrm{X} 22$ & All partial goals emphasise and support the main goal of the company. \\
\hline
\end{tabular}




\section{Case Selection}

The questionnaire respondents were directors or managers of SMEs producing electrical equipment and electronic components in our country. The companies were contacted by email or over the phone and asked to fill out a web-based questionnaire; 60 fully filled questionnaires were received. SMEs are companies with size standard of a maximum of 250 employees. Many of these companies are marked as hi-tech. Characteristics of hi-tech companies in our country or in Germany are similar (e.g. Jangl, 2016).

\section{Data Collection Process}

The level of reliability of the questionnaire tested by the Cronbach's alpha is 0.863. The complete database was analysed by using standard statistical methods such as Spearman's correlation coefficient, logistic regression, and ROC curves (package pROC by Robin et al., 2011), in R (R Core team, 2019).

\section{RESULTS}

\section{Findings}

We used logistic regression which predicts the probability of positive answers (4 and 5 on the Likert scale) on BP items as a function of answers on all IFC items and interactions of answers on items from the narrowed conception of IFC. Sufficient models were identified by a stepwise backward procedure using Akaike information criterion (AIC). Based on deviance the suitability of the models was not rejected at the significance level 0.05 in all cases. The quality of the prediction was assessed by ROC analysis, see Tab. II. All calculations were conducted in $\mathrm{R}$.

II: Quality of prediction of selected logistic regressions identified by AUC, optimal cut-off probability with regard to Youden's index and corresponding sensitivy and specificity

\begin{tabular}{|c|c|c|c|c|}
\hline Item & AUC & Cut-off probability & Sensitivity & Specificity \\
\hline BP3 & $95.44 \%$ & 0.22 & $96.67 \%$ & $86.67 \%$ \\
\hline BP4 & $91.58 \%$ & 0.51 & $85.71 \%$ & $92.31 \%$ \\
\hline
\end{tabular}

III: Parameter estimates together with odds ratio, inverted odds ratio and their significance in sufficient logistic model identified by $A I C$ at $B P 1$

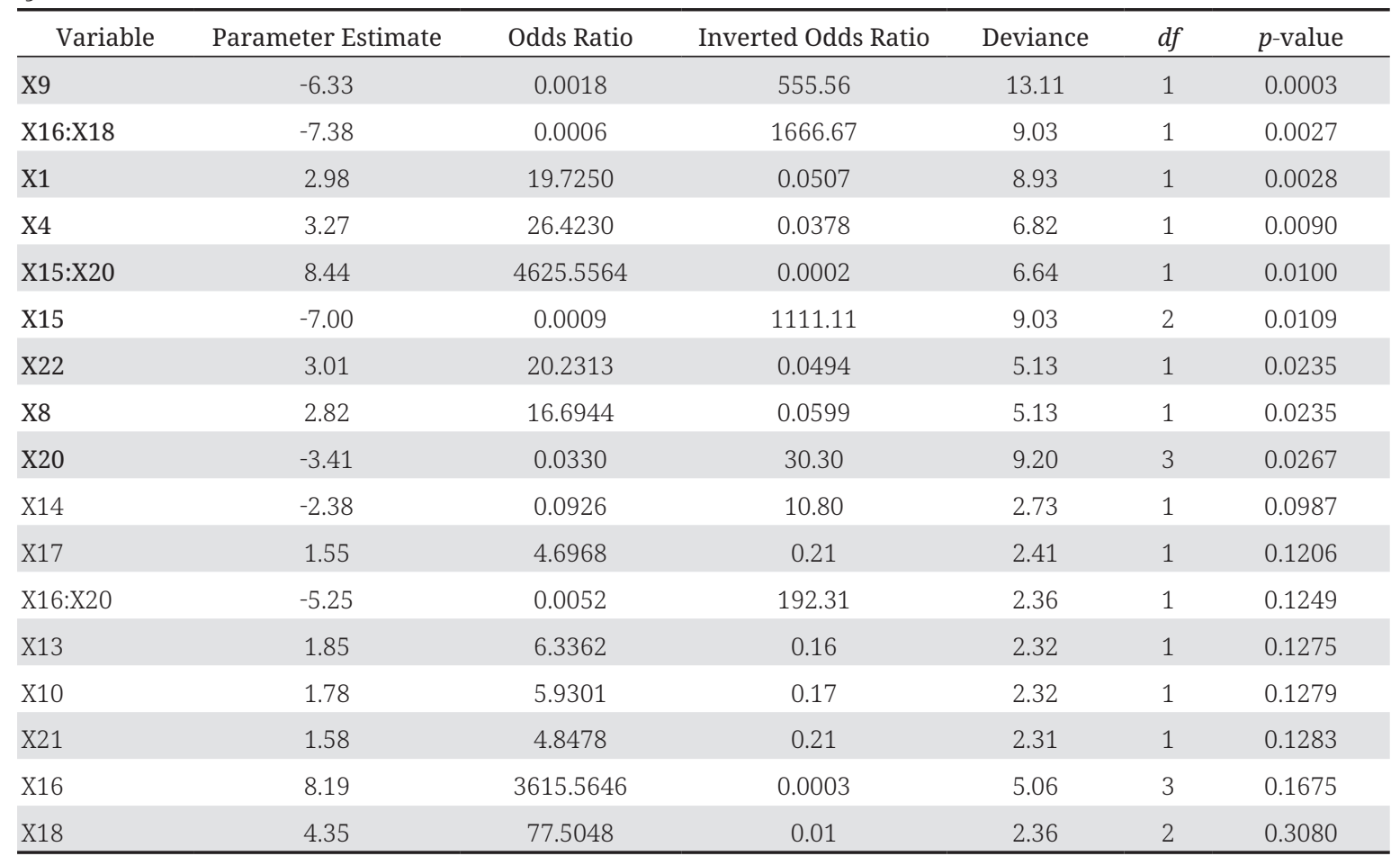

Note, that positive answers to both items X16 and X18 increase the odds of positive vs. another answer to BP1 about 175 times in comparison with a company with nonpositive responses to X16 and X18. Similarly, positive answers at both X15 and X20 decrease the odds of positive vs. another answer to BP1 about seven times in comparison with a company with nonpositive responses to X15 and X20. 
In the following subsections, parameter estimates of the selected models are presented in Tabs. III, V, VI, VII, IX. Notation "." stands for the interaction of two items. The chosen variables are ordered according to their significance, i.e. $p$-value of the deviance based test of individual variables with relevant interactions. The degrees of freedom $(d f)$ of the test are also listed. The significant items in the selected model (at the significance level 0.05) are typed in bold. The influence of the listed items can be assessed by looking at their odds and inverted odds ratios. The results for interactions are commented on in the text separately.

\section{BP1: Company Registers Sales Volume Increase by Current Customers}

From Tab. III, we can conclude on the most significant items increasing the sales volume with current customers. The model shows that all significant items are all items from the narrower conception of IFC without coordination between the departments. The high orientation on some items of the narrower conception of IFC (X15, X20) decreases the odds of increasing the sales volume with current customers. Positive response to X9 has a negative influence on the increase of the sales volume with current customers as well. However, as the results of the models dealing with the other BP items show, the items with a negative influence on BP1 often have a positive influence on the other $\mathrm{BP}$ items. The items from wider conception with the most positive influence BP1 are X1, X4, X22, and X8. Observe, that the model does not include items related to communication, leadership style, and company culture.

\section{BP2: Number of New Customers Increases Year-on-Year}

Due to a convergence problem of the model with all interactions, most of them could not be reflected. Moreover, items X19, X20, and X22 had to be excluded from the model for nonconvergence. However, we have used Spearman correlation to analyse the relationship between these items of IFC and BP2, see Tab. IV. The results show that unlike X20, X19 and X22 have a high positive correlation with increasing number of customers.

Based on Tab. V we can identify items important for increasing the number of new customers. In contrast to the previous model, items related to the narrower conception of IFC (X15 and X18) have a negative influence on BP2. Otherwise, items related to cooperative arrangements (X1 and X2) and $\mathrm{X} 4$ have a positive influence on increasing the number of new customers. Once again, X9 has a negative impact. According to this model, communication, leadership style, company culture, and control are not significant in this case.

\section{BP3: Number of Warranty Claims Decreases}

Due to convergence issues, the parameters of the model with all variables and interactions of items of the narrower conception of IFC could not be estimated. Variable X20 had to be excluded. The Spearman coefficient 0.304 with $p$-value 0.018 suggests that there is no significant dependence between the responses to X20 and BP3.

\section{BP4: ROA Increases Year-on-Year}

Again a problem of convergence of the analysed model with all of the items appeared. For this reason, item X22 had to be omitted. However, using Spearman

IV: Spearman's correlation at items X19, X20 and X22 and BP2

\begin{tabular}{|c|c|c|}
\hline Item & Spearman's correlation & $p$-value \\
\hline X22 & 0.429 & 0.001 \\
\hline
\end{tabular}

V: Parameter estimates together with odds ratio, inverted odds ratio and their significance in sufficient logistic model identified by AIC at BP2

\begin{tabular}{lcccccc}
\hline \multicolumn{1}{c}{ Variable } & Parameter Estimate & Odds Ratio & Inverted Odds Ratio & Deviance & $d f$ & $p$-value \\
\hline X18 & -5.17 & 0.01 & 100 & 16.45 & 1 & 0.0001 \\
X4 & 5.30 & 199.92 & 0.005 & 13.89 & 1 & 0.0002 \\
X15 & -5.07 & 0.01 & 100 & 12.04 & 1 & 0.0005 \\
X2 & 4.41 & 82.40 & 0.012 & 11.07 & 1 & 0.0009 \\
X10 & 3.75 & 42.45 & 0.024 & 0.65 & 1 & 0.0057 \\
X13 & 3.64 & 37.90 & 0.026 & 6.99 & 1 & 0.0082 \\
X1 & 2.13 & 8.45 & 0.122 & 5.25 & 1 \\
X9 & -3.06 & 0.05 & 20 & 4.54 & 1 & 0.0220 \\
\hline
\end{tabular}


VI: Parameter estimates together with odds ratio, inverted odds ratio and their significance in sufficient logistic model identified by AIC at BP3

\begin{tabular}{lcccccc}
\hline \multicolumn{1}{c}{ Variable } & Parameter Estimate & Odds Ratio & Inverted Odds Ratio & Deviance & $d f$ & $p$-value \\
\hline X19 & 3.88 & 48.21 & 0.0207 & 12.56 & 1 & 0.0004 \\
X6 & 4.02 & 55.97 & 0.0179 & 11.88 & 1 & 0.0006 \\
X15:X17 & 7.92 & 2738.12 & 0.0004 & 8.56 & 1 & 0.0034 \\
X17 & -3.89 & 0.02 & 50.0000 & 9.63 & 2 & 0.0081 \\
X14 & 3.18 & 24.15 & 0.0414 & 6.23 & 1 & 0.0126 \\
X15 & -5.28 & 0.01 & 100.0000 & 8.68 & 2 & 0.0130 \\
X10 & -3.03 & 0.05 & 20.0000 & 5.17 & 1 & 0.0230 \\
X16 & 3.60 & 36.71 & 0.0272 & 3.69 & 1 & 0.0549 \\
\hline
\end{tabular}

Note, that positive answers at X15 and X17 decrease the odds of positive vs. another answer on BP3 about 3 times in comparison with a nonpositive answer to item X15 and X17. In Tab. VI we can see a list of significant items with positive (X19, X6, X14) or negative (X15, X17, X10) effect on reduction of warranty claims. Note, that items related to cooperative arrangements, expertise, leadership style, company culture, and control are not included in the sufficient model.

VII: Parameter estimates together with odds ratio, inverted odds ratio and their significance in sufficient logistic model identified by AIC at BP4

\begin{tabular}{lcccccc}
\hline \multicolumn{1}{c}{ Variable } & Parameter Estimate & Odds Ratio & Inverted Odds Ratio & Deviance & $d f$ & $p$-value \\
\hline X12 & -12.92 & $2.4454 \mathrm{E}-06$ & 408931.05 & 17.18 & 1 & $3.4048 \mathrm{E}-05$ \\
X4 & 6.66 & 782.9419 & 0.001 & 11.87 & 1 & 0.0006 \\
X3 & 5.80 & 329.7655 & 0.003 & 8.45 & 1 & 0.0036 \\
X15:X20 & -5.75 & 0.0032 & 312.500 & 8.24 & 1 & 0.0041 \\
X15 & 8.53 & 5050.8719 & 0.0002 & 12.64 & 3 & 0.0055 \\
X20 & 3.87 & 47.7535 & 0.021 & 9.19 & 2 & 0.0101 \\
X15:X16 & -6.99 & 0.0009 & 1111.111 & 6.27 & 1 & 0.0123 \\
X17 & -0.89 & 0.4109 & 2.434 & 8.79 & 2 & 0.0123 \\
X8 & 2.48 & 11.9813 & 0.083 & 5.72 & 1 & 0.0167 \\
X17:X18 & 4.87 & 130.3957 & 0.008 & 5.43 & 1 & 0.0198 \\
X16 & 3.03 & 20.6797 & 0.048 & 7.65 & 2 & 0.0218 \\
X18 & -1.62 & 0.1980 & 5.051 & 5.55 & 2 & 0.0625 \\
X19 & -1.57 & 0.2082 & 4.803 & 2.13 & 1 & 0.1445 \\
\hline
\end{tabular}

correlation (0.563, p-value 0.000) we conclude that item X22 has a strong positive correlation with BP4.

Unlike X22, interactions of items from the narrower conception could have been included in the basic model. Positive responses to X15 and X20 increase the odds of positive vs. another answer on BP4 about 770 times in comparison with a nonpositive answer to item X15 and X20. A similar situation is for X15 and X16 (94 times increase) and the pair of X17 and X18 (640 times increase).

From Tab. VII we can conclude on the most significant factors for increasing profit (ROA). Expenditures on innovation give a reason for observed negative dependence of ROA on X12 in the short-term. Also, items X17 and X18 with negative effect require additional costs. Note, that items related to Expertise and Coordination elements have a positive influence on increasing profit. Further, items X20 and X8 show a significantly positive influence on increasing the profit. This model does not include items related to the cooperative arrangement, communication, ethics, organization structure, and control.

\section{BP5: Production Effectiveness Increases}

The basic model cannot include items X1, X2, and $\mathrm{X} 3$ for convergence reasons, however interactions of items from the narrower conception IFC were studied. Spearman's correlation was used for an analysis of the relationship between X1, X2, X3 and BP5. The results shown in Tab. VIII suggest that X1, $\mathrm{X} 2$, and $\mathrm{X} 3$ have a high positive correlation with increasing the production efficiency.

Based on the results in Tab. IX we can conclude on significant items with positive (X15, X20, X21, $\mathrm{X} 8$ ) and negative (X11, X13, X22, X17) effect on production efficiency. 
VIII: Spearman's correlation at items X1, X2 and X3 and BP5

\begin{tabular}{|c|c|c|}
\hline Item & Spearman's correlation & p-value \\
\hline $\mathrm{X} 1$ & 0.627 & 0.000 \\
\hline $\mathrm{X} 2$ & 0.495 & 0.000 \\
\hline X3 & 0.468 & 0.000 \\
\hline
\end{tabular}

IX: Parameter estimates together with odds ratio, inverted odds ratio and their significance in sufficient logistic model identified by $A I C$ at $B P 5$

\begin{tabular}{lcccccc} 
Variable & Parameter Estimate & Odds Ratio & Inverted Odds Ratio & Deviance & df & $p$-value \\
X15 & 4.84 & 126.45 & 0.01 & 14.20 & 1 & 0.0002 \\
X11 & -5.72 & 0.003 & 333.33 & 13.31 & 1 & 0.0003 \\
X13 & -5.11 & 0.01 & 100.00 & 10.17 & 1 & 0.0014 \\
X20 & 3.78 & 43.78 & 0.02 & 8.57 & 1 & 0.0034 \\
X22 & -4.27 & 0.01 & 100.00 & 6.85 & 1 & 0.0089 \\
X21 & 3.52 & 33.88 & 0.03 & 6.27 & 1 & 0.0123 \\
X17 & -3.29 & 0.04 & 25.00 & 5.49 & 1 & 0.0191 \\
X8 & 2.55 & 12.87 & 0.08 & 5.12 & 1 & 0.0237 \\
X12 & 2.69 & 14.80 & 0.07 & 3.75 & 1 & 0.0529 \\
X18 & 2.01 & 7.49 & 0.14 & 3.51 & 1 & 0.0611 \\
X5 & 2.25 & 9.51 & 0.11 & 3.17 & 1 & 0.0749 \\
X10 & 2.32 & 10.18 & 0.10 & 2.90 & 1 & 0.0884 \\
\hline
\end{tabular}

\section{DISCUSSION}

The results of this paper widen knowledge regarding the relationship between IFC and BP. It was possible to construct a satisfactory model for every item of BP. These models involve the most significant items and interactions influencing the item of BP. Items that have an exclusive positive influence on at least two items of BP are both items of Cooperative arrangement, Expertise, no strict or formal relationship among employees, implementation of gained information into the decisions of the company, and preference of the long-term goals.

It is possible to see that four of these items $(X 2, X 3$, $X 4, X 8)$ are connected with workers or employees in the company. The importance of no strict or formal relationship among employees agrees with conclusions by Helfert et al. (2002). According to them, a high level of strictness and formality can have a negative influence on BP. Kennedy et al. (2003) and Bouachouch and Mamad (2014) note that it is important to have formal and informal contact with workers, which then leads to increased dissemination of information and experience and usage of this information and experience. Formal and informal contacts are necessary for the coordination of the whole company and also for monitoring activities. However, it is possible to conclude that employee attitudes to the company are very important for BP. Tsai et al. (2010) confirmed this result.
Emphasis on education and its positive influence on BP is connected especially with market orientation; for example (Trueman, 2004). He shows that obstructing the education of workers caused by fears of overequipping them with knowledge and skills has a negative effect. Education and training are the main activities for gaining skills. Our result on X2 agrees with conclusions by Mentzer (2001). He stresses that the companies can't use available resources efficiently without planning and organizing all activities and processes.

The next two items of IFC (X1, X16) are connected to the skills and experiences of managers. Separate monitoring of activities connected to different types of business (X1) is the first step to the coordination of all activities in the company. Our results confirm the conclusions of previous pieces of research. Coordination helps managers to realize activities more effectively (Dezso et al., 2012). According to Faraj and Sproull (2000), all skills of managers are relevant for effective team coordination. Kozlowski and Bell (2003) note that managers' coordination skills are a key behavioural ability of a crossfunctional team, which might lead to better team performance and better total BP. Preference of longterm goals (X16) is connected with the vision of the company. A company without goals may occupy a difficult position on the market and increasing BP may also be difficult. Harris (1998) noted that management has to determine a long-term vision. 
Fonfara (2001) continued that management has to choose goals and strategy leading to achieving these goals. All these steps lead to increased BP.

The item with an exclusive negative influence on at least two items of BP is ethical decisions. However, we have a supposed positive relationship between ethics and BP. The main reason is that ethics and ethical decisions in a company can have a positive influence on workers. According to Manurung et al. (2015), workers want to work in keeping with ethical principles and they don't want to disturb these principles. Itani and Inyang (2015) add that stress on ethics can lead to a decrease in stress and internal conflicts. Ethical decisions can lead to increasing the identification of workers with the company or with the team (Cheng and Wang, 2015). Ethics also has a positive effect on the internal and external environment. However, the scientific studies do not analyse the relationship with external stakeholders. Contrarily, our results show a negative relationship between ethical decisions and items of BP connected with sales volume increase either by current or by new customers. This result may be due to ethical decisions having a negative correlation with an item of IFC which has a very strong positive correlation with two items of BP. This item and its relationships need a deeper analysis; the next piece of research may detect if our presumption is correct. According to Chen and Mau (2009) ethical sales behaviour can influence long-term relationships with customers. And one of the main assumptions of a company's success is to have a good long-term relationship with customers.

An unexpected result was the strong negative influence of innovation on increasing profit.
According to Olavarieta and Friedman (1999), innovation and market power are assumed to increase higher BP. Results of the study by Kraśnicka et al. (2018) noticed that the relationship between management innovation and $\mathrm{BP}$ is positive as well. Hernández-Espallardo and Delgado-Ballester (2009) confirmed that small and medium companies have to invest in innovation if they want to remain competitive. Ma and Huang (2016) noticed that innovativeness is important in determining how effectively knowledge can be utilized to identify new opportunities. Even though, the innovation increases the costs in the short term, it brings a positive effect in the long-term horizon. That can be the reason for the negative influence of innovation on increasing profit.

Note also, that the preference of teamwork and mutual cooperation (X7) was not found to be a significant item among all considered items of IFC in any of BP models. However, in our sample, we observed a significant positive correlation with item X2, X5, X10, X13, X14, X16, X19, and X22 which are mostly connected with the working environment in the company. That explains why $\mathrm{X} 7$ was not necessarily observed to be significant in any model of BP items' responses. This result agrees with conclusions by Wang et al. (2017) which analysed streamlined IFC at industrial SMEs. It depends on the situation, when to use the streamlined IFC approach and to attune to firmspecific circumstances. It is confirmed that only preference of teamwork and mutual cooperation can not lead to increasing BP.

\section{CONCLUSION}

\section{Theoretical Contributions}

The results contribute knowledge to theory and praxis. The most important result of this paper for the theory is that satisfactory models for predicting each of five of the BP items reflecting selected IFC items were identified. Most of the models also include interactions. The items of BP are divided into financial performance and marketing performance. Homburg and Pflesser (2000) or Matear et al. (2002) noted that marketing performance contributes to financial performance.

\section{Managerial Implications}

These results can be applied in praxis. Companies have to make a decision on which items of BP are the most important for them. The first step to a successful company is to know what the main goal of the company is and what the managers want to achieve. According to this, managers of the companies can aim to achieve this BP using information from the model. In other words, it is possible to focus on the items of IFC which have a significantly positive influence on this type of BP; and eliminate items of IFC which have a negative influence on this type of BP.

It is evident that all items of IFC are significant; its importance may change in time. An item such as innovation has only a negative influence on the profitability of a company in the short term; however, a company without innovation will not be successful in the long term. This is the problem in all of the indicators of BP. The next research can be aimed at the problematic analysis of indicators of $\mathrm{BP}$ in the short and long term. 
Acknowledgements

Lucie Kaňovská contributed in the research, which was held in 60 SMEs companies producing electrical equipment and electronic components in the Czech Republic, South Moravia Region.

\section{REFERENCES}

AKIMOVA, I. 2000. Development of market orientation and competitiveness of Ukrainian firms. European Journal of Marketing, 34(9/10): 1128-1148.

BAKER, W. E. and SINKULA, J. M. 2009. The complementary effects of market orientation and entrepreneurial orientation on profitability in small businesses. Journal of Small Business Management, 47(4): 443-464.

BOUACHOUCH, M. and MAMAD, M. 2014. Analysis of the antecedents of inter-functional coordination in the supply chain context: Case of the medicament flows in a Moroccan university hospital. International Journal of Business and Management, 9(8): 97-107.

BOURANTA, N., MAVRIDOGLOU, G. and KYRIAZOPOULOS, P. 2005. The impact of internal marketing to market orientation concept and their effects to bank performance. Operational Research: An International Journal, 5(2): 349-62.

CARRASCO, G., ANGELES, A. and MARROQUIN-TOVAR, E. 2016. Inflexibility in organizational decision-making. Journal of Business Economics and Management, 17(4): 564-579.

CARUANA, A. and CALLEYA, P. 1998. The effect of internal marketing on organisational commitment among retail bank managers. International Journal of Bank Marketing, 16(3): 108-116.

CHEN, M.-F. and MAU, L.-H. 2009. The impacts of ethical sales behaviour on customer loyalty in the life insurance industry. The Service Industries Journal, 29(1): 59-74.

CHENG, M.-Y. and WANG, L. 2015. The mediating effect of ethical climate on the relationship between paternalistic leadership and team identification: A team-level analysis in the Chinese context. Journal of Business Ethics, 129(3): 639-654.

DEZSO, C. L., GROHSJEAN, T. and KRETSCHMER, T. 2012. Coordination experience and team performance: evidence from the electronic games industry. Robert H. Smith School Research Paper. RHS 06-136. Robert H. Smith School.

FARAJ, S. and SPROULL, L. 2000. Coordinating expertise in software development teams. Journal of Management Science, 46(12): 1554-1568.

FONFARA, K. 2001. Evaluations of market orientations in companies. Contemporary methodological dilemmas and challenges. Economics and Business Review, 1(1): 31-47.

GERINGER, J. M. and HEBERT, L. 1991. Measuring performance of international joint ventures. Journal of International Business Studies 22(2): 249-263.

GRAY, B., MATEAR, S., BOSHOFF, C. and MATHESON, P. 1998. Developing a better measure of market orientation. European Journal of Marketing, 32(9/10): 884-903.

GRIMMER, L., MILES, M. P., BYROM, J. and GRIMMER, M. 2017. The impact of resources and strategic orientation on small retail firm performance. Journal of Small and Business Management, 55(1): 7-26.

HAJJAT, M. M. 2002. Customer orientation: Construction and validation of the CUSTOR scale. Marketing Intelligence and Planning, 20(7): 428-441.

HARRIS, L. 1998. Cultural domination: The key to market-oriented culture? European Journal of Marketing, 32(3/4): 354-373.

HARRISON-WALKER, J. L. 2001. The measurement of a market orientation and its impact on business performance. Journal of Quality Management, 6(2): 137-172.

HELFERT, G., RITTER, T. and WALTER, A. 2002. Redefining market orientation from a relationship perspective. European Journal of Marketing, 36(9/10): 1119-1139.

HERNÁNDEZ-ESPALLARDO, M. and DELGADO-BALLESTER, E. 2009. Product innovation in small manufacturers, market orientation and the industry's five competitive forces: Empirical evidence from Spain. European Journal of Innovation Management, 12(4): 470-491.

HOMBURG, C. and PFLESSER, C. 2000. A multiple-layer model of market-oriented organizational culture: Measurement issues and performance outcomes. Journal of Marketing Research, 37(4): 449-462.

ITANI, O. and INYANG, A. 2015. The effects of empathy and listening of salespeople on relationship quality in the retail banking industry. International Journal of Bank Marketing, 33(6): 692-716.

JANGL, P. 2016. Model of Market Orientation of High-Tech Firms in Germany: Validation Study. Business: Theory and Practice, 17(3): 216-224. 
KAURA, V., DURGA PRASAD, C. S. and SHARMA, S. 2015. Service quality, service convenience, price and fairness, customer loyalty, and the mediating role of customer satisfaction. International Journal of Bank Marketing, 33(4): 404-422.

KENNEDY, K. N., GOOLSBY, J. R. and ARNOULD, E. J. 2003. Implementing a customer orientation: Extension of theory and application. Journal of Marketing, 67(4): 67-81.

KOHLI, A. K., JAWORSKI, B. J. and KUMAR, A. 1993. MARKOR: A measure of market orientation. Journal of Marketing Research, 30(4): 467-477.

KOZLOWSKI, S. W. J. and BELL, B. S. 2003. Work groups and teams in organizations. In: BORMAN, W., ILGEN, D. and KLIMOSKI, R. (Eds.), Handbook of psychology: Industrial and organizational psychology. London: Wiley, pp. 333-375.

KRAŚNICKA, T., GŁÓD, W. and WRONKA-POŚPIECH, M. 2018. Management innovation, proinnovation organisational culture and enterprise performance: testing the mediation effect. Review of Managerial Science, 12(3): 737-769.

LAWRENCE, P. and LORSCH, J. 1967. Differentiation and integration in complex organizations. Administrative Science Quarterly, 12(1): 1-47.

MA, R. and HUANG, Y.-C. 2016. Opportunity-based strategic orientation, knowledge acquisition, and entrepreneurial alertness: The perspective of the global sourcing suppliers in China. Journal of Small Business Management, 54(3): 953-972.

MALTZ, E. and KOHLI, A. K. 1996. Market intelligence dissemination across functional boundaries. Journal of Marketing Research, 33(1): 47-61.

MANURUNG, D., SUHARTADI, A. R. and SAEFUDIN, N. 2015. The influence of organizational commitment on employee fraud with effectiveness of internal control and organizational justice as a moderating variable. Procedia-Social and Behavioral Sciences, 211(25): 1064-1072.

MATEAR, S., OSBORNE, P., GARRETT, T. and GRAY, B.J. 2002. How does market orientation contribute to service firm performance? An examination of alternative mechanisms. European Journal of Marketing, 36(9/10): 1058-1075.

MENGUC, B. and AUH, S. 2008. Conflict, leadership, and market orientation. International Journal of Research in Marketing, 25(1): 34-45.

MENTZER, J. T. 2001. Supply chain management. SAGE London.

MIN, S., MENTZER, J.T. and LADD, R.T.J. 2007. A market orientation in supply chain management. Journal of the Academy of Marketing Science, 35(4):507-522.

MOHR, J. J., SENGUPTA, S. and SLATER, S. 2013. Marketing of high technology products and innovations. $3^{\text {rd }}$ Edition. England: Pearson.

MOHSEN, K. and ENG, T. 2013. Enhancing inter functional coordination and marketing performance: Utilization of the motivation/ability/opportunity framework. EBS Working Papers WP2013-9. University of Essex Colchester.

MONTOYA-WEISS, M. M., MASSEY, A. P. and SONG, M. 2001. Getting it together: Temporal coordination and conflict management in global virtual teams. Academy of Management Journal, 44(6): 12511262.

NARVER, J. C. and SLATER, S. F. 1990. The effect of a market orientation on business profitability. Journal of Marketing, 54(4): 20-35.

OLAVARIETA, S. and FRIEDMANN, R. 1999. Market-oriented culture, knowledge related resources, reputation assets and superior performance: a conceptual framework. Journal of Strategic Marketing, 7(4): 215-228.

PAVLÁKOVÁ DOČEKALOVÁ, M., KOCMANOVÁ, A., ŠIMBEROVÁ, I. and KOLEŇÁK, J. 2018. Modelling of Social Key Performance Indicators of Corporate Sustainability Performance. Acta Universitatis Agriculturae et Silviculturae Mendelianae Brunensis, 66(1): 303-312.

PENG, C. and GEORGE, R. T. 2011. The effect of inter-functional coordination on organizational commitment in the hotel industry. Scholarworks. Available at: https://pdfs.semanticscholar.org/ e09e/854ac1d6b435d5d6384ab761b7c002bf6df9.pdf [Accessed: 2020, January 15].

R CORE TEAM, 2019. R: A language and environment for statistical computing. Vienna, Austria: $\mathrm{R}$ Foundation for Statistical Computing. Available at: https://www.R-project.org/ [Accessed: 2020, January 15].

ROBIN, X., TURCK, N., HAINARD, A., TIBERTI, N., LISACEK, F., SANCHEZ, J. C. and MÜLLER M. 2011. pROC: an open-source package for R and S+ to analyze and compare ROC curves. BMC Bioinformatics, 12: 77.

SZYMANSKI, D. M. and HENARD, D. H. 2001. Customer satisfaction: A meta-analysis of the empirical evidence. Journal of the Academy of Marketing Science, 29(1): 16-35. 
SALYOVA, S., TABORECKA-PETROVICOVA, J., NEDELOVA, G. and DADO, J. 2015. Effect of Marketing Orientation on Business Performance: A Study from Slovak Foodstuff Industry. Procedia Economics and Finance, 34: 622-629.

TANG, Z. and TANG, J. 2012. Entrepreneurial orientation and SME performance in China's changing environment: The moderating effects of strategies. Asia Pacific Journal of Management, 29(2): 409431.

TAY, J. Y. W. and TAY, L. 2007. Market orientation and the property development business in Singapore. International Journal of Strategic Property Management, 11(1): 1-16.

TOMASKOVA, E. 2005. Measuring of market orientation and its influence on business performance. Brno: Vutium.

TRUEMAN, K. 2004. Market-orientation and local government. Barriers and constraints. Political Studies Association, 1: 1-12.

TSAI, C. J., EDWARDS, P., SENGUPTA, S. 2010. The associations between organisational performance, employee attitudes and human resource management practices. Journal of General Management, 36(1): 1-20.

UBREŽIOVÁ, I., KURČOVÁ, R. and HORVÁTHOVÁ, J. 2017. How Can We See the Corporate Social Responsibility within Its Application in Business Practice? Acta Universitatis Agriculturae et Silviculturae Mendelianae Brunensis, 65(1): 0339-0346.

VÁZQUEZ, R., ÁLVAREZ, L. I. and SANTOS, M. L. 2002. Market orientation and social services in private non-profit organisations. European Journal of Marketing, 36(9/10): 1022-1046.

WANG, Y. J., LAPLACA, P., ZHU, Y., HAO, A. W., GUO, C. and BAO, Y. 2017. Streamlining interfunctional coordination in industrial SMEs. Journal of General Management, 42(3): 31-40.

WOODSIDE, A. G. 2005. Firm orientations, innovativeness, and business performance: Advancing a system dynamics view following a comment on Hult, Hurley, and Knight's 2004 study. Industrial Marketing Management, 34(3): 275-279.

ZAHRA, S. A. and GEORGE, G. 2002. Absorptive capacity: A review, reconceptualization, and extension. The Academy of Management Review, 27(2): 185-203.

Contact information

Zuzana Hübnerová: hubnerova@fme.vutbr.cz

Eva Tomášková: eva.tomaskova@law.muni.cz

Josef Bednář: bednar@fme.vutbr.cz 